EGU2020-19697

EGU General Assembly 2020

(c) Author(s) 2020. This work is distributed under

the Creative Commons Attribution 4.0 License.

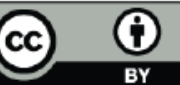

\title{
Tree Monitoring Using Ground Penetrating Radar: Two Case Studies Using Reverse-Time Migration
}

\author{
Iraklis Giannakis, Fabio Tosti, Lilong Zou, Livia Lantini, and Amir M. Alani \\ School of Computing and Engineering, University of West London (UWL), London, United Kingdom of Great Britain and \\ Northern Ireland (Iraklis.Giannakis@uwl.ac.uk; Fabio.Tosti@uwl.ac.uk; Lilong.Zou@uwl.ac.uk; Livia.Lantini@uwl.ac.uk; \\ Amir.Alani@uwl.ac.uk)
}

Non-destructive testing (NDT) for health monitoring of trees is a suitable candidate for detecting signs of early decay [1]. Recent developments $[2,3,4]$ have highlighted that ground-penetrating radar (GPR) has the potential to provide with a robust and accurate detection tool with minimum computational and operational requirements in the field. In particular, a processing framework is suggested in [2] that can effectively remove ringing noise and unwanted clutter. Subsequently, an arc length parameterisation is employed in order to utilise a wheel-measurement device to accurately position the measured traces. Lastly, two migration schemes; Kirchhoff and reversetime migration, are successfully applied on numerical and laboratory data in [3].

In the current paper, the detection scheme described in [2,3] using reverse-time migration is tested in two case studies that involve diseased urban trees within the greater London area, UK (Kensington and Gunnersbury park). Both of the trees were cut down after the completion of the measurements and furthermore cut into several slices to get direct information with regards to their internal structure. The processing scheme described in $[3,4]$ managed to adequately detect the internal decay present in both trees. The aforementioned case studies provide coherent evidences to support the premise that GPR is capable of detecting decay in diseased trunks and therefore has the potential to become an accurate and efficient diagnostic tool against emerging infectious diseases of trees.

\section{Acknowledgements}

The authors would like to express their sincere thanks and gratitude to the following trusts, charities, organizations and individuals for their generosity in supporting this project: Lord Faringdon Charitable Trust, The Schroder Foundation, Cazenove Charitable Trust, Ernest Cook, Sir Henry Keswick, Ian Bond, P. F. Charitable Trust, Prospect Investment Manage- ment Limited, The Adrian Swire Charitable Trust, The John Swire 1989 Charitable Trust, The Sackler Trust, The Tanlaw Foundation and The Wyfold Charitable Trust.

This paper is dedicated to the memory of Jonathon West, a friend, a colleague, a forester, a conservationist and an environmentalist who died following an accident in the woodland that he loved. 


\section{References}

[1] P. Niemz, D. Mannesm, "Non-destructive testing of wood and wood-based materials," J. Cult. Heritage, vol. 13, pp. S26-S34, 2012.

[2] I. Giannakis, F. Tosti, L. Lantini and A. M. Alani, "Health Monitoring of Tree Trunks Using Ground Penetrating Radar," IEEE Transactions on Geoscience and Remote Sensing, vol. 57, no. 10, pp. 8317-8326, 2019.

[3] I. Giannakis, F. Tosti, L. Lantini and A. M. Alani, "Diagnosing Emerging Infectious Diseases of Trees Using Ground Penetrating Radar," IEEE Transactions on Geoscience and Remote Sensing, Early Access, doi: 10.1109/TGRS.2019.2944070

[4] A. M. Alani, F. Soldovieri, I. Catapano, I. Giannakos, G. Gennarelli, L. Lantini, G. Ludeno and F. Tosti, "The Use of Ground Penetrating Radar and Microwave Tomography for the Detection of Decay and Cavities in Tree Trunks," Remote Sensing, vol. 11, no. 18, 2019. 